Part of Journal of Research of the National Bureau of Standards, Volume 27, July 1941

\title{
EFFECT OF THE CHEMICAL DURABILITY OF GLASS ON THE ASYMMETRY POTENTIAL AND REVERSIBILITY OF THE GLASS ELECTRODE
}

\author{
By Edgar H. Hamilton and Donald Hubbard
}

\section{ABSTRACT}

Departures from a linear relation between the voltage of the glass electrode and the $\mathrm{pH}$ of alkaline solutions were approximately proportional to the amount of attack on the glass by the solution, as measured by the interferometer. The departures were less before than after the electrode had been immersed in a highly alkaline solution, and the drift of the potential at a constant $\mathrm{pH}$ was most marked with high alkalinity, indicating that nonreproducibility of voltage was associated with chemical attack on the glass. Differences in the capacities of the two surfaces of electrode bulbs of Corning 015 glass to absorb ions, as shown by the absorption of an organic dye, may be the cause of asymmetry potential.

\section{CONTENTS}

I. Introduction

II. Experimental procedure

III. Reversibility

IV. Comparison of voltage departures and chemical durability ...... $\quad 29$

1. Data and results

2. Discussion of results _... 30

V. Differences in inner and outer surfaces of electrode bulbs_....... 30

1. Measurement of dye absorption . .

2. Possible relationship to asymmetry potential 31

3. Effect of alteration of outer surface 32

VI. Conclusions _.......

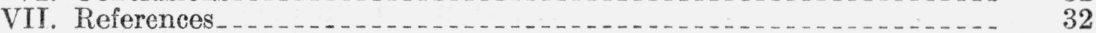

\section{INTRODUCTION}

The glass electrode is subject to voltage departures from the straightline relation of the Nernst equation in the $\mathrm{pH}$ ranges below 2 and above 9 [1], ${ }^{1}$ and also in solutions of high salt concentrations [2]. Previous work has demonstrated that these voltage departures are always associated with changes in the chemical durability of the glass from which the electrodes are made [3]. Other conspicuous features of the glass electrode are a gradual potential drift and irreversibility in the alkaline range and an asymmetry potential. That these phenomena might also be associated with the chemical durability of the glass is suggested by this earlier work.

\section{EXPERIMENTAL PROCEDURE}

The glass used throughout this investigation was Corning 015 [4]. All emf measurements were made at room temperature with a portable

\footnotetext{
${ }_{1}$ Figures in brackets indicate the literature references at the end of this paper.
} 
potentiometer-electrometer. The $\mathrm{pH}$ determinations were obtained by means of a hydrogen electrode, with a saturated calomel half-cell as a reference electrode.

Durability measurements, for studying the relation between voltage departure and chemical durability, were made by the interferometer method [3, 5]. The dye-absorption method with Victoria Blue B, which has been used successfully for rating the relative durability of glass containers of similar composition [6], was applied for differentiating between the inner and outer surfaces of blown bulbs.

\section{REVERSIBILITY}

All of the electrodes of Corning 015 glass used in this investigation show a certain degree of irreversibility at any given $\mathrm{pH}$ in the high-

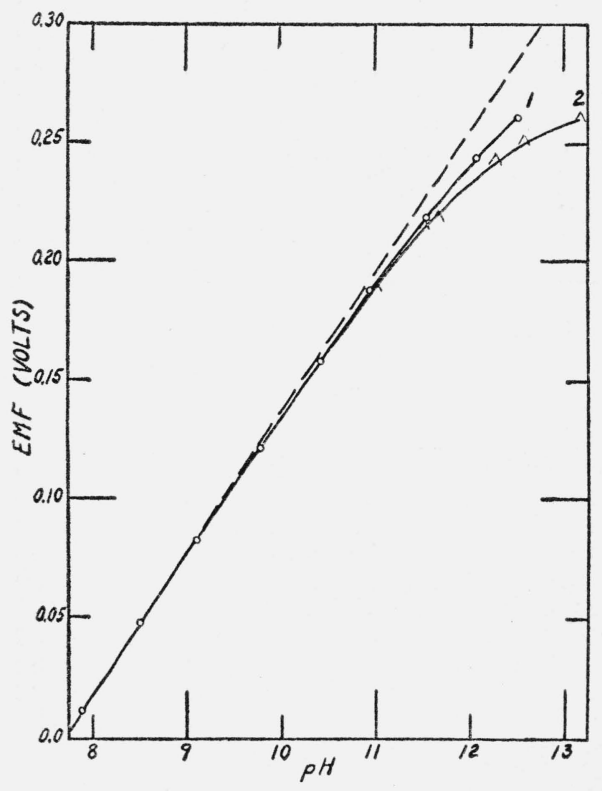

FIGURE 1.-Emf-pH relation of the glass electrode in the alkaline range.

(All potentials corrected to $25^{\circ} \mathrm{C}$.)

$\mathrm{O}$, Increasing $\mathrm{pH}$ obtained by $\mathrm{HAc}+\mathrm{NaOH}$.

$\wedge$, Decreasing pH obtained by $\mathrm{NaOH}+\mathrm{HAc}$.

alkaline region in addition to a voltage departure. At $\mathrm{pH} \mathrm{12,}$ for example, the voltage departure depends on whether the electrode has been brought from a more acid medium or a more alkaline one. In addition to this, the voltage of the electrode in strongly alkaline solution does not remain constant, but undergoes a voltage drift, the rate of which is partially determined by the alkalinity. Such behavior is to be expected if the glass electrode is undergoing attack by the solution.

To study this irreversibility, a solution of $0.2 N$ acetic acid was titrated with $0.2 \mathrm{~N} \mathrm{NaOH}$. At suitable stages of the titration, simultaneous $\mathrm{pH}$ determinations of the solution and emf readings of the glass electrode immersed in it were made. The titration was continued up to a $\mathrm{pH}$ of 12.5. At the end of this experiment, the same electrode was placed in a sodium hydroxide solution of $\mathrm{pH}$ 13.2. This solution was then titrated with acetic acid, and $\mathrm{pH}$ and emf readings made as before, until the solution had reached a $\mathrm{pH}$ of 11.2.

The data plotted in figure 1 show the $\mathrm{pH}$-emf relation and the voltage departures of the glass electrode in the alkaline range in the presence of $\mathrm{Na}^{+}$ions. As the alkalinity is increased to $\mathrm{pH} 12.5$, 
accompanied by an increase in $\mathrm{Na}^{+}$ion concentration, the departure from the straight-line relation increases; and, conversely, as the alkalinity is decreased from $\mathrm{pH} 13.2$ by the addition of acetic acid, the voltage departure decreases, but in this latter case the voltage departure at a given $\mathrm{pH}$ is always the greater. This lack of reversibility no doubt accounts for the greater part of the differences between the voltage departures reported by various investigators $[2,3,4]$.

\section{COMPARISON OF VOLTAGE DEPARTURES AND CHEMICAL DURABILITY}

\section{DATA AND RESULTS}

In order to determine what relation exists between the voltage departures and the chemical durability of the electrode glass, durability measurements obtained on Corning 015 glass by the interferometer method were compared with voltage departures reported by MacInnes and Dole [4], and Dole [2], and those, shown in figure 1 , obtained by the authors. The departure data were interpolated to the $\mathrm{pH}$ values at which durability measurements were made. The durabilities were measured at $80^{\circ} \mathrm{C}$, but it has been shown that attack on the glass at any other temperature can be approximated from the equation: Attack $b \cdot 2(\mathrm{t} / 10)$ [5], in which $b$ is a constant and $t$ is the temperature in degrees centigrade. Such durability values calculated for $25^{\circ} \mathrm{C}$ are given in the third column of table 1 , and plotted against voltage departures in figure 2. Although the electrode readings were taken after a short exposure and durability measurements were for a 6 -hour period, a comparison is justifiable, because the amount of attack is directly pro-

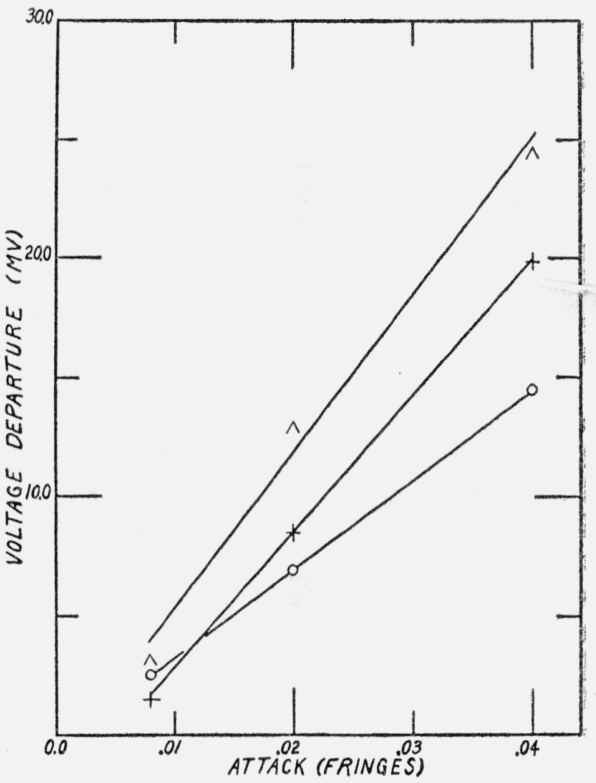

FIgure 2.-Relation between voltage departures of the glass electrode and the chemical durability of the electrode glass.

(Calculated to $25^{\circ} \mathrm{C}$ ). Sources of voltage departure data: $\mathrm{O}$, Curve 1 of figure 1 .

t, D. A. MacInnes and M. Dole.

$\wedge$, M. Dole.

portional to the duration of exposure. Figure 2 shows that the relationship between voltage departure and attack is linear within the limits of error for measuring the attack. 
TABLE 1.-Voltage departures of the glass electrode and the chemical durability of Corning 015 electrode glass

\begin{tabular}{|c|c|c|c|c|c|}
\hline \multirow{2}{*}{$\mathrm{pH}$} & \multicolumn{2}{|c|}{ Attack in 6 hours at- } & \multicolumn{3}{|c|}{$\begin{array}{l}\text { Voltage departures at } 25^{\circ} \mathrm{C} \text { as } \\
\text { reported by- }\end{array}$} \\
\hline & $\begin{array}{l}80^{\circ} \mathrm{C} \text { (deter- } \\
\text { mined) }\end{array}$ & $\begin{array}{l}25^{\circ} \mathrm{C} \text { (calcu- } \\
\text { lated) a }\end{array}$ & $\begin{array}{l}\text { Curve } 1 \\
\text { figure } 1\end{array}$ & $\begin{array}{c}\text { Macinnes b } \\
\text { and Dole }\end{array}$ & Dole c \\
\hline $\begin{array}{r}9.9 \\
11.2 \\
12.0\end{array}$ & $\begin{array}{c}\text { Fringes } \\
0.35 \\
90 \\
1.75,1.90\end{array}$ & $\begin{array}{c}\text { Fringes } \\
0.008 \\
.020 \\
.040\end{array}$ & $\begin{array}{r}m v \\
2.5 \\
7.0 \\
14.5\end{array}$ & $\begin{array}{r}m v \\
1.5 \\
8.6 \\
19.9\end{array}$ & $\begin{array}{r}m v \\
3.0 \\
12.8 \\
24.3\end{array}$ \\
\hline
\end{tabular}

a Attack $=b \cdot 2^{(t / 10)}$, where $b$ is a constant and $t$ is the temperature in degrees centigrade. b J. Am. Chem. Soc. 5\%, 35 (1930), figure 3, curve B.

- J. Am. Chem. Soc. 53, 4266 (1931), figure 2, bottom curve.

\section{DISCUSSION OF RESULTS}

Any quantitative relation between voltage departures and chemical durability must, of necessity, not be accepted too rigorously, since:

1. The glass is not entirely uniform and contains many cords and striae, which make an estimate of the amount of shift in the interferometer fringes difficult.

2. Voltage departures and chemical durability must be determined on separate specimens, blown bulbs in the first case and cloth-polished flats in the latter.

3. The slight drift in the potential of the glass electrode in the alkaline range raises a question as to its true potential.

The amount of attack on the electrode by the solution is actually very minute. One fringe is equal to approximately 0.29 micron, and the density of the glass is 2.5. From these data, it can be calculated that 1.83 fringes, the attack at $\mathrm{pH} 12$ at $80^{\circ} \mathrm{C}$ for 6 hours, is equal to $0.133 \mathrm{mg}$ of glass per square centimeter of surface. The rate of attack would be much slower at $25^{\circ} \mathrm{C}$, at which temperature the electrode measurements were made. A calculation based on the effect of temperature on the chemical durability of Corning 015 glass [5] gives 0.04 fringe, or $0.0029 \mathrm{mg}$ of glass per square centimeter, as the amount of attack by the above solution in 6 hours at $25^{\circ} \mathrm{C}$. This very low solution rate may account for the slowness of the potential drift of the glass electrode [4].

\section{DIFFERENCES IN INNER AND OUTER SURFACES OF ELECTRODE BULBS}

\section{MEASUREMENT OF DYE ABSORPTION}

Since the voltage anomalies of the glass electrode have been definitely associated with changes in the chemical durability of the glass from which these electrodes are made, it is logical to look to chemical durability for an explanation of the asymmetry potential of the glass electrode. It has been demonstrated that in the $\mathrm{pH}$ range 2 to 7 the electrode glass exhibits a slight uniform swelling [3]. If it can also be demonstrated that the two surfaces of a glass electrode are different, as, for instance, in their abilities to swell or to absorb ions from a solution, this difference might account for the "asymmetry potential" - that is, the potential which is obtained when the inner and outer surfaces of the electrode bulb are in contact with the same solution. 
We have previously observed that the outer surface of a glass bottle is much more durable than its inner surface, unless the latter has been especially treated. To determine if the same condition exists in electrode bulbs, large bulbs (50- to $100-\mathrm{ml}$ capacity) of Corning 015 glass were blown on the end of soft glass tubes (15-mm inside diameter). The bulbs were filled with a $\mathrm{pH} 6$ sodium-potassium phthalate buffer and suspended in a Pyrex beaker containing the same buffer solution $[6,7]$. The assembly was placed in a thermostated water bath at $80^{\circ} \mathrm{C}$ for 24 hours. At the end of this period the buffer was removed and the bulbs were rinsed thoroughly with hot distilled water. Both surfaces of the bulbs were dyed at room temperature for 30 minutes in a 0.06-percent aqueous solution of Victoria Blue B (a basic dye) containing $1 \mathrm{ml}$ of acetic acid per $100 \mathrm{ml}$ of solution. All excess dye was removed by rinsing 3 to 4 times with distilled water, followed by two 10-minute extractions with distilled water. All dye on the surfaces of the soft glass tubing was removed by swabbing with alcohol-saturated cotton wads. The dye absorbed on the surfaces of the bulbs was extracted in known volumes of 95-percent ethanol. The amount of dye was determined by measuring the light absorbed by the alcoholic solutions with the aid of a photoelectric cell, using an incandescent lamp as a light source and a light filter composed of Corning glasses G34Y and G555Q. From table 2, it may be seen that the amount of dye absorbed by the inner surfaces was from 19 to 36 times that absorbed by the outer surfaces of the respective bulbs.

TABLE 2.-Comparison of chemical durability of inner and outer surfaces of bulbs of Corning 015 glass as indicated by absorption of Victoria Blue B dye

\begin{tabular}{|c|c|c|c|}
\hline \multirow{2}{*}{ Bulb } & \multicolumn{2}{|c|}{ Dye absorbed by- } & \multirow{2}{*}{ Ratio $I / O$} \\
\cline { 2 - 3 } & $\begin{array}{c}\text { Inner surface, } \\
I\end{array}$ & $\begin{array}{c}\text { Outer surface, } \\
O\end{array}$ & \\
\hline & $m g$ & $m g$ & \\
\hline & 0.355 & 0.019 & 18.7 \\
$B^{*}$ & .407 & .016 & 25.5 \\
\hline & .310 & .015 & 20.7 \\
& .535 & .015 & 35.6 \\
\hline
\end{tabular}

This difference between the two surfaces is due to the treatment $o$ the glass during the blowing process. The outer surface was formed from glass in or near the outer surface of the button. During the heating of the glass to its working temperature, the volatile constituents in the surface of the button are continuously being removed by the stream of hot gases from the flame. The glass which forms the inner surface of the bulb is not exposed to this stream of hot gases, and therefore its composition is not altered, or at least not to such an extent as the glass in the outer surface.

\section{POSSIBLE RELATIONSHIP TO ASYMMETRY POTENTIAL}

When a glass electrode bulb is filled with and placed in water, or an aqueous solution of $\mathrm{pH} 2$ to 7 , both surfaces will absorb ions and swelling will take place. Since the inner surface is capable of absorbing a different quantity of ions than the outer surface, as indicated by the Victoria Blue $B$ test, the inner surface will assume a charge of dif$321517-41-3$ 
ferent magnitude than the outer surface. Such a condition will give rise to a potential difference between the two surfaces and is probably the source of the asymmetry potential.

\section{EFFECT OF ALTERATION OF OUTER SURFACE}

Any change in the solution in which the electrode is immersed which affects the chemical nature of the outer surface will necessarily affect its absorbing ability and hence the voltage at this surface. Such is the case in the alkaline range, in which the more durable silica layer is dissolved. The magnitude of this change in the surface can be qualitatively visualized by noting that the ability to absorb Victoria Blue $B$ dye is completely eliminated when the glass surface has been exposed to $\mathrm{NaOH}$. Since the inner surface of the electrode bulb is always in contact with the same solution, the changes in the outer surface are probably the largest sources of voltage departures of the glass electrode.

\section{CONCLUSIONS}

The outer surface of the bulb of a glass electrode is attacked appreciably when immersed in alkaline solutions of $\mathrm{pH}$ greater than about 9. Since a marked voltage departure, proportional to the rate of attack, occurs in this region, it is reasonable to consider that the voltage departure is a result of the attack and depends on the chemical durability of the glass. A simple and satisfactory explanation of the voltage departure is thus obtained.

The conclusion is drawn that the asymmetry potential of the glass electrode results from differences in the ability of the inner and outer surfaces of the electrode to absorb ions.

\section{REFERENCES}

[1] D. A. MacInnes and D. Belcher, Further studies on the glass electrode, J. Am. Chem. Soc. 53, 3315 (1931).

[2] Malcolm Dole, The theory of the glass electrode, J. Am. Chem. Soc. 53, 4260 (1931).

[3] Donald Hubbard, Edgar H. Hamilton, and Alfred N. Finn, Effect of the solubility of glass on the behavior of the glass electrode, J. Research NBS 2\%, 339 (1939) RP1187.

[4] D. A. MacInnes and Malcolm Dole, The behavior of glass electrodes of different compositions, J. Am. Chem. Soc. 52, 29 (1930).

[5] Donald Hubbard and Edgar H. Hamilton, Chemical durability of glass by the interferometer method, J. Research NBS ₹y (1941) RP1409.

[6] E. H. Hamilton and A. N. Finn, Relative solubility of glass in acid solutions as indicated by dye absorption, Glass Ind. 19, 179 (1938).

[i] H. T. S. Britton, Hydrogen Ions, table 44, p. 220. (D. Van Nostrand Co., New York City, 1932).

Washington, April 26, 1941. 